\title{
Demand Response Model for Hardware Implementation
}

\author{
B. Capitão \\ ISEL-Instituto Superior de \\ Engenharia de Lisboa, Instituto \\ Politécnico de Lisboa \\ 1950-005 Lisboa, Portugal \\ A44737@alunos.isel.pt
}

\author{
J. Lagarto \\ ISEL-Instituto Superior de \\ Engenharia de Lisboa, Instituto \\ Politécnico de Lisboa \\ 1950-005 Lisboa, Portugal \\ joao.lagarto@isel.pt \\ P.M.Fonte \\ ISEL-Instituto Superior de \\ Engenharia de Lisboa, Instituto \\ Politécnico de Lisboa \\ 1950-005 Lisboa, Portugal \\ pedro.fonte@isel.pt
}

\author{
R. Pereira \\ ISEL-Instituto Superior de \\ Engenharia de Lisboa, Instituto \\ Politécnico de Lisboa \\ 1950-005 Lisboa, Portugal \\ rita.pereira@isel.pt
}

\author{
P. Almeida \\ ISEL-Instituto Superior de \\ Engenharia de Lisboa, Instituto \\ Politécnico de Lisboa \\ 1950-005 Lisboa, Portugal \\ palmeida@sa.isel.pt
}

\begin{abstract}
Demand response actions allow to support an adequate domestic load management, considering consumer preferences. In order to develop a hardware tool based on Arduino used to support consumers load management and decisions, an optimization mathematical model is developed and detailed in this paper. In the developed mathematical model, household appliances and electric vehicle are considered as controllable loads. The existence of a storage system based on batteries is considered as well as energy provided by the power grid and solar panel self-generation. The model is implemented using optimization software GAMS (General Algebraic Modeling System) as a Mixed Integer Programming (MIP) problem, where its outputs are used as inputs applied to the hardware used as interface between the optimization mathematical model and controllable loads.
\end{abstract}

Keywords - Demand response, Load management, Mixed Integer Programming,

\section{INTRODUCTION}

Demand response (DR) is used as a mean of consumption peak reduction promoting energy efficiency [1]. Peak reduction contributes to minimize investment in production centers and in transmission lines allowing to use stored energy when consumption increases occur. Energy efficiency, in its turn, intends to mitigate energy losses in the transmission lines and promote consumption pattern changes accordingly with the local renewable generation availability. These measures have environmental impact and contribute for the urgent needed climate changes measures, by using renewable energies, deferring new pollutants power plants installation [2] and decongesting power networks. To accomplish this impact, domestic load management is useful to achieve peak consumption reductions, to efficiently shift loads, contributing to the load diagram flattening [3]. It is also intended that by performing domestic load management, consumers are able to reduce their energy bill, through the domestic loads'

This paper was funded by IDI\&CA - Lisbon Polytechnique Institute and by national funds through FCT - Fundação para a Ciência e Tecnologia, under projects UIDB $/ 50021 / 2020$ consumption allocation in those time periods where the energy price is lower [4]. However, it really matters to develop algorithms that allow consumers to keep load management autonomy, guaranteeing and enhancing their wellbeing. In addition, the existence of an adequate interface tool between the mathematical algorithm, controllable loads (CL) and the consumer itself, is preponderant to domestic consumers' inclusion into load management and to consolidate consumers as active stakeholders in the power grid management [5].

Different criteria is used to classify DR programs, mainly because these programs are developed to provide answers to specific scenarios, however some convergence can be found in literature around two major types: time-based-programs (TBP), also known as price-based-programs (PBP) [6,7] and incentivebased-programs (IBP) [8]. When DR is price-based, consumers are more subject to price fluctuations and load control decisions are more limited [9]. When DR is incentive based, the load control is performed accordingly with power grid events, i.e, for example, when more congestion is verified, the utility can drive consumers to a more adequate consumption profile, through a load shifting action [10]. In [11], TBP encompasses time-of-use, real time pricing and critical peak pricing programs. On the other hand, IBP encompasses direct load control, interruptible service, demand bidding, emergency demand response, capacity market and ancillary service market.

Despite the increasing number of DR programs in the last decade, such as the ones referred in [12] and also mentioned in [13], in this paper the addressed DR model can be classified as TBP, because domestic consumers are able to change consumption patterns driven by the energy price. In this case, price is the trigger that leaded to the DR model development proposed in this paper. The energy price mainly derives from the utility policies, the wholesale market, self-generation systems and energy storage systems. However, for domestic consumer's load management it is directly related with energy prices, 
therefore the existence of self-generation and storage system increases the load management options regarding the intended energy bill reduction, or environmental concerns.

The addressed DR model is developed with the purpose of providing a tool that gives support to domestic consumers decisions regarding CL management, without the need of a deep technological knowledge, allowing the inclusion of a hardware interface between this DR model and the domestic load appliances chosen as CL. To accomplish this domestic consumers' supporting tool, dedicated hardware will be designed and assembled to act as a load management interface. Initial system configuration and setup is done using an EXCEL spreadsheet that generates a set of configuration text files, which are then transferred to the interface load management hardware via a standard micro SD card. The interface load management hardware will consist of an ATMEL ATMEGA 328P microcontroller, running at $16 \mathrm{MHz}$; a Real Time Clock based on the DS3231 from Maxim Integrated with battery backup; an USB to serial interface based on the FT232R from FTDI Chip and 6 output relays (SPDT) one for each considered CL. This low cost prototype, of approximately $50 €$, can be easily installed contributing for a wider domestic load management systems implementation. The system formed by the DR model, interface hardware and the domestic loads defined as CL is designed having into account a simple and economic solution, when compared with the ones already available in the market.

This paper is organized as follows: in section II load management model is addressed, characterizing the considered CL, storage and self-generation system; in section III two case studies are analysed considering the storage system influence into the load management model. Finally, in section IV some conclusions about the developed work are discussed.

\section{LOAD MANAGEMENT MODEL}

In this paper the optimization mathematical model is based on [6] and is developed considering 6 domestic CL, detailed in Table 1. For the optimization algorithm, CL are characterized by their rated power, operation time and working time scheduling defined by a starting and ending time. The operation time corresponds to appliances' working time, while the working time scheduling refers to the defined time period where the appliances are allowed to work. Both operation time and working time scheduling are defined by the consumer.

\section{TABLE I. DOMESTIC CL OPERATION CHARACTERISTICS}

\begin{tabular}{|l|c|c|c|c|}
\hline \multicolumn{1}{|c|}{$\begin{array}{c}\text { Controllable } \\
\text { loads }\end{array}$} & $\begin{array}{c}\text { Power } \\
\text { (kW) }\end{array}$ & $\begin{array}{c}\text { Operation } \\
\text { time (h) }\end{array}$ & $\begin{array}{c}\text { Starting } \\
\text { time (h) }\end{array}$ & $\begin{array}{c}\text { Ending } \\
\text { time (h) }\end{array}$ \\
\hline Oven & 2.4 & 0.5 & $15: 00$ & $19: 00$ \\
\hline Water heater & 2.0 & 3 & $03: 00$ & $07: 00$ \\
\hline Washing machine & 2.4 & 2 & $00: 00$ & $07: 00$ \\
\hline Drying machine & 2.0 & 1 & $00: 00$ & $07: 00$ \\
\hline Dish washer & 2.0 & 2 & $17: 00$ & $21: 00$ \\
\hline EV charger & 4.6 & 7 & $00: 00$ & $09: 00$ \\
\hline
\end{tabular}

For the domestic load management model it is considered $10.35 \mathrm{~kW}$ of contracted power and a tariff that settles lower energy prices between 22:00 and 08:00, $10.09 \mathrm{c} € / \mathrm{kWh}$, corresponding to off-peak hours and higher energy prices for all the other hours, $19.48 \mathrm{c} € / \mathrm{kWh}$, corresponding to peak hours. Also, it is considered a $2 \mathrm{kWh}$ Li-ion batteries storage system with a charge/discharge cycle efficiency of $81 \%$, and the existence of self-generation given by $1.5 \mathrm{~kW}$ of PV solar panel installed power. The total daily power generation from the solar panel is $7.73 \mathrm{kWh}$. The excess generation can be sold to the grid at a price of $4.72 \mathrm{c} € / \mathrm{kWh}$. There is a base consumption that is given by non-controllable loads (NCL) consumption power, such as lights, refrigerator and computer, for example. The total daily consumption of the CL and NCL is $66.91 \mathrm{kWh}$.

The optimization model considers consumer's net revenue maximization, i.e., the maximization of the difference between the revenue obtained from selling the excess generation to the grid and buying electricity costs, subject to a set of constraints. The mathematical formulation of the developed model is given by (1-16), where the variables and explanation of each equation are given at the end of the addressed mathematical formulation.

$$
\underset{P v_{t}, P c_{t}}{\operatorname{Max}} L=\sum_{t=1}^{T}\left(\lambda v_{t} \cdot P v_{t}-\lambda c_{t} \cdot P c_{t}\right)
$$

s.t.

$$
\begin{gathered}
P c_{t}+P d c h_{t}+P g_{t}=P v_{t}+P c h_{t}+P c l_{t}+P n c l_{t} \\
P c l_{t}=\sum_{j=1}^{J}\left(P_{j} \cdot u_{j, t}\right)
\end{gathered}
$$

$$
0 \leq P c_{t} \leq P \text { cont } \cdot u c_{t}
$$

$0 \leq P v_{t} \leq P$ cont $\cdot u v_{t}$

$$
\begin{gathered}
0 \leq P c h_{t} \leq P c h^{\max } \cdot u c h_{t} \\
0 \leq P d c h_{t} \leq P d c h^{\max } \cdot u d c h_{t} \\
\sum_{t=1}^{T} u_{j, t}=4 r_{j} \\
\sum_{t=k}^{k+4 r_{j}-1} u_{j, t} \geq 4 r_{j}\left(u_{j, k}-u_{j, k-1}\right)
\end{gathered}
$$




$$
\begin{gathered}
u_{j, t}=0, t>4 f_{j} \text { and } t<4 s_{j} \\
u_{\text {,Washing machine' }{ }^{\prime}}+u_{\text {'Drying machine }{ }^{\prime}, t} \leq 1 \\
u c_{t}+u v_{t} \leq 1 \\
u c h_{t}+u d c h_{t} \leq 1 \\
W_{t}=W_{t-1}+P c h_{t} \cdot \eta c h-\frac{P d c h_{t}}{\eta d c h} \\
W_{t=0}=W_{t=T} \\
W^{\text {min }} \leq W_{t} \leq W^{\text {max }}
\end{gathered}
$$

Where, (1) represents the consumer's net revenue, $L$, obtained for the simulation period $T$, where $\lambda v_{t}$ and $\lambda c_{t}$ are the energy selling and buying price, respectively; $P v_{t}$ and $P c_{t}$ are the power sold and bought from the grid, respectively, all of them considered at a time instant $t$, that in this paper is set to a 15-minute time period.

Equation (2) is the balance equation, where $P d c h_{t}$ is batteries' discharged power, $P g_{t}$ is the power produced by the PV solar panel, $P c h_{t}$ is the batteries' charged power, and $P c l_{t}$ and $\mathrm{Pncl}_{t}$ are the CL and NCL power consumption, respectively.

The power consumption of CL that are working is given by (3), where $P_{j}$ is the power consumption of controllable load $j$ and $u_{j, t}$ is a binary variable that is equal to $0 / 1$ if controllable load $j$ is off/on.

The set of equations 4 to 7 refers to the limits of the buying and selling power, and with the limits of batteries' charging and discharging power, respectively. In these equations, Pcont is the contracted power, $P c h^{\max }$ and $P d c h^{\max }$ are the batteries maximum charge and discharge powers. $u c_{t}, u v_{t}, u c h_{t}$ and $u d c h_{t}$ are binary variables equal to 1 when the consumer is buying power from the grid, selling power to the grid, the battery is charging, and the battery is discharging (in this order). Otherwise, these values are settled to 0 .

Equations 8 to 10 refers to operation $\left(r_{j}\right)$, starting $\left(s_{j}\right)$ and ending $\left(f_{j}\right)$ times of the controllable load $j$.
Equation (11) prevents the washing and the dryer machines from working simultaneously.

Equations (12) and (13) prevent the simultaneity of buying and selling power, and of charging and discharging batteries, respectively.

Finally, equations 14 to 16 are related with the batteries' energy storage. Equation (14) accounts for the energy stored in each instant $t, W_{t}$, where $\eta c h$ and $\eta d c h$ are the batteries charging and discharging efficiencies, respectively. Equation (15) sets the batteries energy stored limits between a minimum $\left(W^{\text {min }}\right)$ and a maximum ( $W^{\max }$ ) value. Equation (16) assures that batteries' energy storage has the same value at the beginning and at the end of simulation period.

\section{CASE STUDIES ANALYSIS AND DISCUSSION}

For the load management model addressed in section II, two different case studies were considered regarding the existence or not of a battery storage system and its impact into the CL distribution along a $24 \mathrm{~h}$ period. This period was chosen because, as referred in section II, there are different energy prices during 24h. Lower energy prices are settled between 22:00 and 08:00, during week days and weekends, and for that reason is considered that consumption pattern remains constant during the week. This means that the most relevant loads, i.e., the ones with higher energy consumption values such as the washing machine, for example, show similar consumption pattern during the week.

\section{A. Case study with storage system}

Considering the existence of the storage system described in section II, the mathematical model outputs are shown in Fig. 1 to Fig. 3.

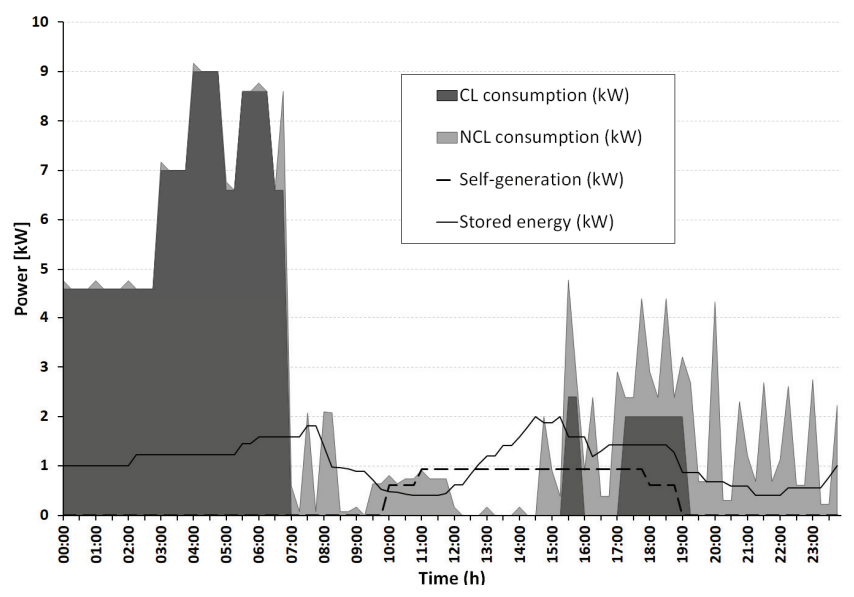

Fig. 1. Power consumption, self-generation and stored energy distribution.

In Fig. 1, the load diagram outline for CL and NCL, including self-generation and the system stored energy can be observed. The founded relation between sold and bought power in order to supply the overall consumption needs are shown in Fig. 2, and the resulting CL distribution can be observed in Fig. 3 , where the on/off working status is given by the binary variable, as considered in section II . 


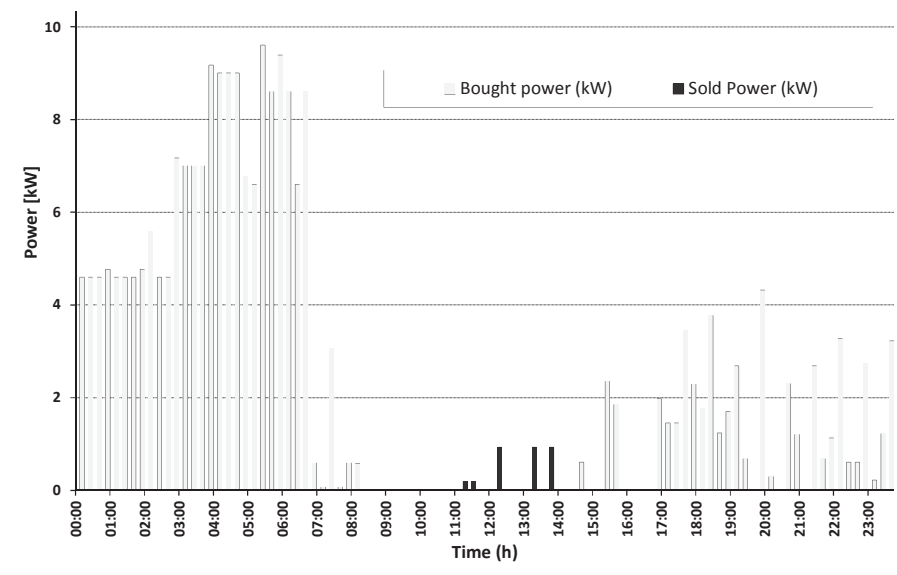

Fig. 2. Relation between bought and sold power considering energy storage system.

From Fig. 1 and Fig. 2, it can be observed that CL are working within the time periods defined in table 1 and that bought energy is used to accomplish consumption needs and to store energy. This is mainly noticeable between 00:00 and 07:00, where the CL are working. Self-generation is used to fulfill NCL consumption needs and to increase consumers profit by selling the remaining energy to the power grid. In addition, is also used to charge the batteries, when no NCL consumption is verified, avoiding buying energy during peak periods. Stored energy management is optimized regarding not only CL and NCL consumption, but mainly considering energy bought and selling prices, where the corresponding bought and sold energy is addressed in Fig. 2. In Fig. 3 can be observed the simultaneous work of several CL, which naturally contributes for the power consumption highest values observed between 00:00 and 07:00, however these values are inferior to the considered contracted power, as expected.

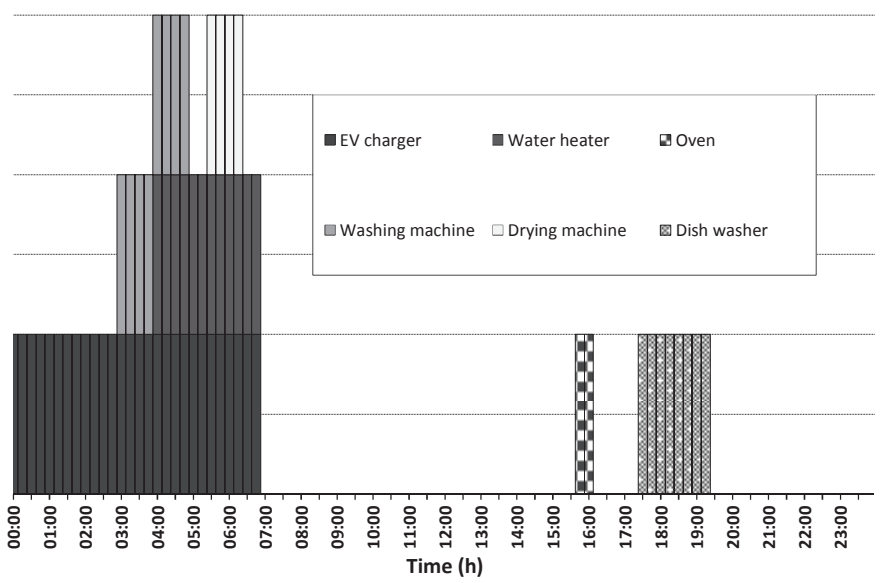

Fig. 3. Controllable loads working status and distribution.

\section{B. Case study without storage system}

Considering the inexistence of storage system, the corresponding optimization mathematical outputs with the adequate simplifications are shown in Fig. 4 to Fig.6.

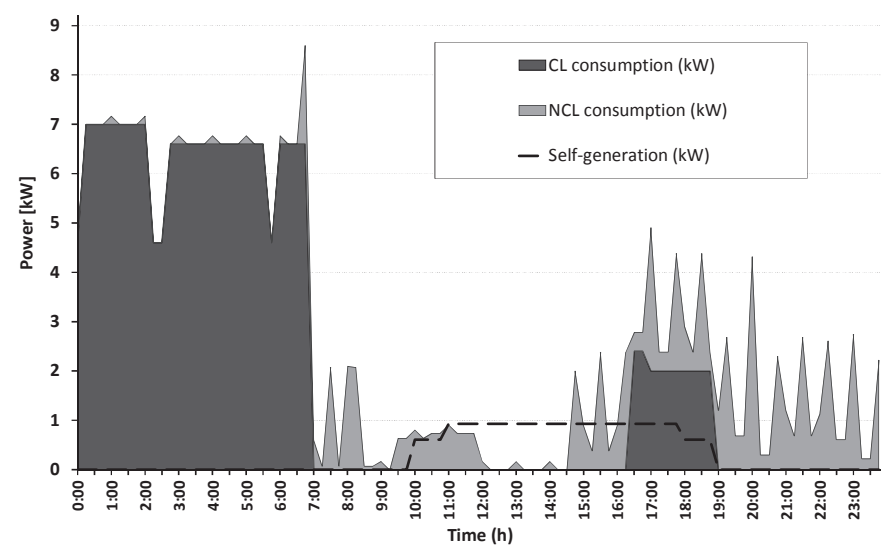

Fig. 4. Power consumption and self-gneration distribution.

In Fig. 4, it can be observed that power consumption peak is reduced in order to minimize bought power, as shown between 00:00 and 07:00, in Fig. 5. This means that CL distribution is performed in order to assign CL consumption mainly during off-peak hours and also in time periods where is possible to take advantage of self-generation. In this case study, self-generation is mainly used to assure consumption demand, as shown in Fig. 5 (between 11:00 and 14:00), rather than being also used for energy storage, as observed in the previous analyzed case study.

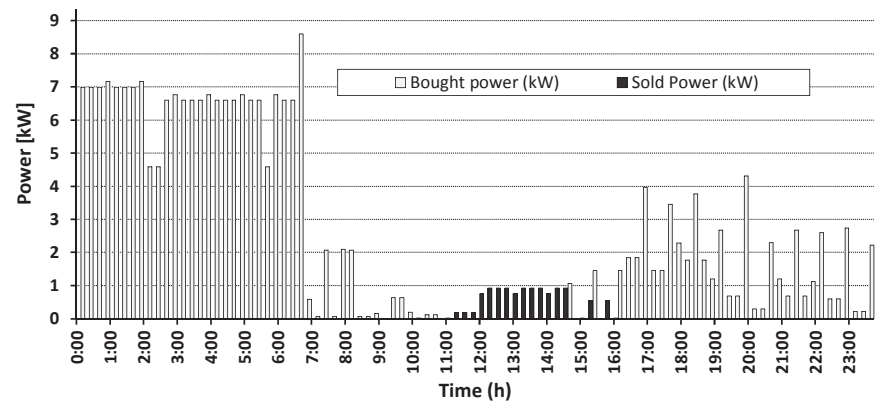

Fig. 5. Relation between bought and sold power.

The corresponding CL distribution is shown in Fig. 6, where the on/off working status is given by the binary variable, as considered in section II.

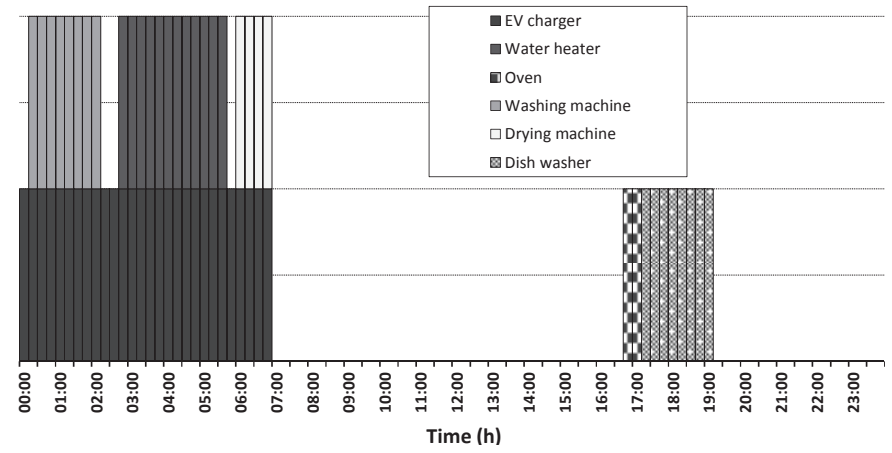

Fig. 6. Controllable loads working status and distribution. 


\section{Case study overall comparison}

Considering CL and NCL consumption, self-generation, sold and bought power, and considering the existence of a storage system, the results can be observed in Fig. 7.

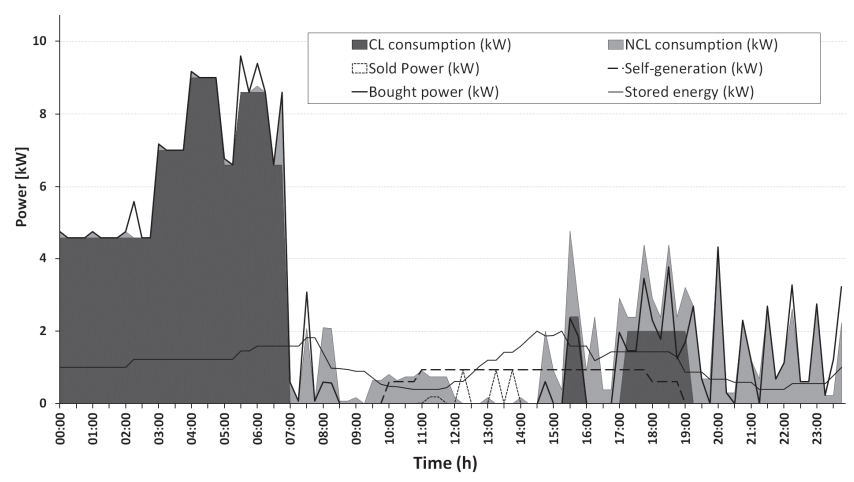

Fig. 7. Power consumption, self-geration, stored energy, bought and sold power distribution.

For the same considerations, but without the existence of a storage system, results can be observed in Fig. 8 .

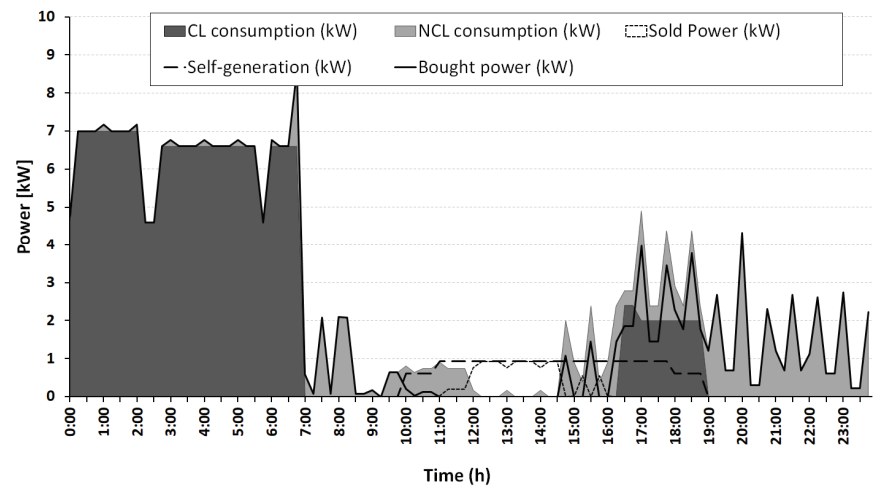

Fig. 8. Power consumption, self-geration, bought and sold power distribution.

Observing Fig. 7 and Fig. 8, it can be noticed that sold power is more significant in the absence of a storage system. In fact, without the storage system the energy sold during the day is 2.86 $\mathrm{kWh}$, while with the storage system it is $0.78 \mathrm{kWh}$, meaning that it is preferable to store energy to be used afterwards during peak hours when the energy bought is more expensive, rather than sell it to the power grid. Also, it can be observed in Fig. 8 that bought power is only used to fulfill load demand, as expected. However, the energy bought from the grid is higher without the storage system $(62.01 \mathrm{~kW})$ than with the storage system $(60.67 \mathrm{kWh})$, since the consumer can not use the stored energy in peak hours. The load management system including the storage system allows the consumer to decrease its energy bill approximately $9.4 €$ in one month.

\section{CONCLUSIONS}

The developed work showed an optimization mathematical model that allowed to perform CL management. The $\mathrm{CL}$ operation time frame and predefined working periods are defined by the consumer. This model was implemented using GAMS software, and the obtained results showed a consumers' net revenue maximization, with the allocated CL in those defined time periods. In addition, results showed that consumption power is always below the contracted power limit. From this work, it is also possible to infer that the addition of a storage system supporting self-generation contributes for energy bill reduction, where the increment of self-generation energy is preponderant for achieving even better results. The mathematical model outputs are adequate being applied directly into a low-cost hardware interface tool prototype that will be implemented in a near future, showing that it is possible to widen CL management concept because it is possible to gather larger domestic consumers groups.

\section{REFERENCES}

[1] Y. Huang, H. Tian,, L. Wang, "Demand Response for Home Energy Management System", Electrical Power and Energy Systems, vol. 73, 2015, pp. 448-455.

[2] R. Pereira, A. Fagundes, R. Melício, V.M.F. Mendes, J. Figueiredo, J. Martins, J.C. Quadrado, "Demand response analysis in smart grids resorting to fuzzy clustering model", in Contribution to Technological Innovation, Eds. L.M. Camarinha-Matos, S. Tomic, P. Graça, Springer, Heidelberg, 2015, pp. 403-412.

[3] M.A.F. Ghazvini, J. Soares, O. Abrishambaf, R. Castro, Z. Vale, “ Demand Response Implementation in Smart Households", in Energy and Buildings, vol. 143, 2017,129-148.

[4] R. Pereira, R. Melício, V.M.F. Mendes, J. Figueiredo, J. Martins, J.C. Quadrado, "Consumer Energy Management System with Integration of Smart Meters" in Energy Reports vol. 1, 2015, pp.22-29.

[5] S. Singh, A. Namboordiri, M.P. Selvan, "Simplified Algorithm for Dynamic Demand Response in Samrt Homes Under Smart Grid Environment", IEEE PES Grand International Conference and Exposition Asia, pp. 1-7, Bangkok, May 2019

[6] M. Songa, K. Alvehaga, J. Widénb, A. Parisio, "Estimating the impacts of demand response by simulating household behaviours under price and CO2 signals"in Electr. Power Syst. Res. vol.111, 2014, pp. 103-114.

[7] M. H. Albadi, , E.F. El-Saadany, "A summary of demand response in electricity markets" in Electr. Power Syst. Res., vol.78 (11), 2008, pp. 1898-1996.

[8] J. Wang, S. Kennedy, J. Kirtley, "Optimization of Time-Based Rates in forward energy markets", IEEE International Conference on the European Energy Market, pp. 1-7, Madrid, June 2010

[9] U.S. Department of Energy, Benefits of demand response in electricity markets and recommendations for achieving them, 2006, in press.

[10] C. Vivekananthan ; Y. Mishra ; G. Ledwich ; F. Li, "Demand Response for Residential Appliances via Customer Reward Scheme", in IEEE Transactions on Smart Grid, vol.5 (2), 2014, pp 809-820.

[11] H.A. Aalami, M. Parsa Moghaddam, G.R.Yousefi, "Demand response modeling considering Interruptible/Curtailable loads and capacity market programs", in Applied Energy, vol. 87 (1), 2010, pp. 243-250.

[12] P. Siano, "Demand response and smart grids-A survey", in Renewable and Sustainable Energy Reviews, Vol. 30, 2014, pp. 461-468.

[13] J. Aghaei, M. Alizadeh, "Demand response in smart electricity grids equipped with renewable energy sources: A review", in Renewable and Sustainable Energy Reviews, vol.18, 2013,pp. 64-72. 